\title{
Loline alkaloids for better protection of pastures from insect pests
}

\author{
H.S. EASTON ${ }^{1}$, T.B. LYONS ${ }^{1}$, B.M. COOPER ${ }^{2}$ and W.J. MACE ${ }^{1}$ \\ ${ }^{1}$ AgResearch Ltd, Private Bag 11008, Palmerston North 4442, New Zealand \\ ${ }^{2}$ AgResearch Ltd, Kerikeri, New Zealand \\ sydney.easton@agresearch.co.nz
}

\begin{abstract}
Loline alkaloids are non-toxic to livestock and protect endophyte-infected fescue against insects. They are not present in perennial ryegrass (PRG) infected with its natural endophyte. PRG has been artificially infected with the loline-producing endophyte AR525, sourced from tall fescue. One loline structure, $N$-formyl loline, is regularly expressed in AR525-infected PRG herbage but at lower concentrations than in tall fescue. There is significant variation between infected PRG families, and data indicate improved mean herbage concentrations in response to selection. Transmission of AR525 to seed of infected PRG plants is variable. Infection frequencies above $90 \%$ are achieved for some families, but the variation is not under simple genetic control, and there are as yet undetermined environmental influences. PRG infected with loline-producing endophytes will be a valuable future option for farmers, but to be viable on farms requires higher herbage loline concentrations and better seed transmission.
\end{abstract}

Keywords: endophyte, ryegrass, lolines, host-symbiont interaction

\section{Introduction}

Perennial ryegrass (PRG) (Lolium perenne) and tall fescue are infected with endophytic fungi of the genus Neotyphodium (Easton et al. 2001). The species that infect tall and meadow fescues (Festuca arundinacea and $F$. pratensis; syn Lolium arundinaceum and $L$. pratense) produce loline alkaloids that have potent activity against insect pests of pasture, but have no known adverse effects on vertebrate livestock (Bush et al. 1997). There are commonly three different loline structures found in endophyte-infected tall and meadow fescue, $N$-formyl loline, $N$-acetyl loline and $\mathrm{N}$-acetyl norloline. The presence and concentrations of individual structures vary with endophyte strain and host (Ball \& Tapper 1999; Bush et al. 1993). The PRG endophyte, $N$. lolii, also protects its host from insect attack (Popay \& Mainland 1991; Prestidge et al. 1982), but the most potent bioactive molecules produced by the PRG association, lolitrem B and ergovaline, are also detrimental to livestock (Fletcher \& Harvey 1981). AR1 endophyte produces neither of these compounds, relying on production of peramine to protect its host (Popay et al. 1999). Peramine is another alkaloid present in both ryegrass and tall fescue associations that is non-toxic to vertebrates but is an effective feeding deterrent against some insects. Protection based on peramine alone is not as robust as that offered when more potent compounds are present.

Naturally, Neotyphodium endophytes are transmitted only through seed, but grass seedlings can be artificially infected by inoculation with cultured fungus (Latch \& Christensen 1985), isolated from the same or related host species (Christensen 1995).

PRG has been inoculated with Neotyphodium strains isolated from tall fescue that produce lolines and peramine but not ergovaline. Peramine was produced in abundance (Easton 2007) with herbage concentrations typical of those found in PRG associations, rather than the lower concentrations typical of tall fescue associations. Lolines were also detected in much lower concentrations than found in tall fescue.

PRG was inoculated with several endophyte strains isolated from tall fescue (W.R. Simpson, M.J. Christensen \& G.C.M. Latch pers. comm.), seed was produced and progenies were grown in rows on light volcanic soils at Kerikeri. After 3 years, some rows were observed to survive better than others (B.M. Cooper unpublished data). Among the lines present in these rows was PRG infected with AR525, a strain of the 'clavi-plus' class of Neotyphodium coenophialum (B.A. Tapper unpublished data). Some surviving plants were used in crosses to other PRG, and further PRG material was inoculated with AR525. Earlier data sets with this material have been described (Easton et al. 2007). This paper presents further data.

\section{Materials and Methods 2006-2007}

PRG plants of seven half-sibling (HS) families (Easton et al. 2007) infected with Neotyphodium strain AR525 endophyte ex-tall fescue were sampled in October 2006 by cutting to $1 \mathrm{~cm}$ above the soil surface. Leaf sheath samples were roughly separated from leaf blade, frozen and freeze dried, and analysed for loline concentrations by a modification of the gas chromatography methods of Kennedy \& Bush (1983) and Yates et al. (1989). Thirty plants with higher concentrations, representing all seven families, were isolated for seed production. Up to 48 seeds of each of 31 HS families harvested in January 
Table 1

$N$-formyl loline concentrations of 22 half-sibling perennial ryegrass families infected with endophyte strain AR525, October 2007.

\begin{tabular}{lc}
\hline & $\begin{array}{c}N \text {-formyl loline } \\
\text { concentrations }(\mu \mathrm{g} / \mathrm{g})\end{array}$ \\
\hline Grand mean & 257 \\
Highest family mean & 419 \\
Lowest family mean & 106 \\
$\mathrm{LSD}_{5 \%}$ family means & 94 \\
Highest maternal lineage mean & 311 \\
Lowest maternal lineage mean & 164 \\
\hline
\end{tabular}

2007 were germinated in nursery trays in April 2007. One tiller per seedling was assayed by immuno-blot (Wheatley \& Simpson 2000) for endophyte infection. Three hundred infected seedlings from 20 families with highest mean infection frequencies were potted and kept through the winter, on an outside concrete pad at Palmerston North. In September 2007, five tillers of each plant were screened for endophyte infection, and any with less than four of five tillers infected were discarded.

\section{7-2008}

Plants identified above as having at least four tillers infected of the five inspected were sampled in October 2007 and analysed for loline concentration as described above. HS family groups were compared for loline concentrations, and selected plants were inter-pollinated in two groups, a small elite group of 12 plants with high concentrations, and a larger group of 36 with lower, but still above mean, concentrations. Seed was harvested in January 2008. Up to 48 seedlings in two replicates of 24 for each of 48 HS families were grown and tested for endophyte infection (April 2008) by immuno-blot of one tiller per seedling. After discarding endophytefree seedlings, the two replicates of each family were bulk sampled for loline analysis (May 2008). Infection frequencies of HS families were compared by both chisquare of consolidated family data and by ANOVA of individual replicate frequencies. Plants from the elite isolation were held through the winter.

\section{8-2009}

The above plants were sampled again in October 2008 ( 8 months old) and assayed for loline concentration. A subset was selected for high loline concentration and for their origin in HS families with high infection frequencies. These plants were isolated, seed was harvested in January 2009, and up to 96 seedlings per family sown in February were tested for endophyte infection in April 2009, by blotting one tiller.
Table 2 Frequency of infection of perennial ryegrass seedlings with endophyte strain AR525, 48 half sibling families, April 2008.

\begin{tabular}{lc}
\hline & $\begin{array}{c}\text { Frequency of } \\
\text { endophyte infection \% }\end{array}$ \\
\hline Grand mean & 53 \\
Highest family mean & 89 \\
Lowest family mean & 7 \\
\hline
\end{tabular}

\section{Results}

$\mathrm{N}$-formyl loline (NFL) was expressed throughout the material assayed, but at lower concentrations than would be expected of tall fescue infected with the same endophyte strain. No other loline structures were detected.

Two of 31 families examined in April 2007 were found to be free of infection. Among the remaining 29 families, 64\% (601/946) of seedlings were infected. Of the 300 plants retained, on the basis of blotting one tiller, only eight showed less than four of five tillers clearly infected the following September, and these were discarded. The 292 plants remaining belonged to 22 HS families, and families varied four-fold for NFL concentrations when sampled in October $(\mathrm{P}<0.0001$; Table 1). However, grouping the HS families according to maternal lineage a further generation back, did not uncover $(\mathrm{P}=0.20)$ the higher level of discrimination expected if simple genetic effects were operating.

Mean infection frequency of HS families assayed in April 2008 was 53\% (Table 2). Infection frequencies of the 48 families varied significantly, by both of the statistical methods applied. However, grouping the families according to maternal lineage revealed no significant differences between groups $(\mathrm{P}=0.61)$.

Analysis of samples taken from young seedlings in May 2008 showed a moderately high mean concentration of NFL (Table 3), but no differences between HS families $(\mathrm{P}=0.63)$ or between the elite and second isolations. Analysis of samples from a sub-set of the same families (the elite isolation) in September 2008, showed lower mean concentrations (Table 3), but significant differences between families and an indicative correlation ( $\mathrm{P}=0.055$, one-tailed test) with the non-significant May results.

Seedlings assayed for endophyte infection in April 2009 showed a mean infection frequency of $75 \%$. This varied significantly between families (Table 4), but grouping the families according to maternal lineage revealed no significant differences between groups $(\mathrm{P}=0.82)$. 
Table $3 \quad N$-formyl loline concentrations of half-sibling perennial ryegrass families infected with endophyte strain AR525, May and September 2008.

\begin{tabular}{llc}
\hline & & $\begin{array}{c}N \text {-formyl loline } \\
\text { concentrations }(\mu \mathrm{g} / \mathrm{g})\end{array}$ \\
\hline $\begin{array}{l}\text { May 2008, bulked } \\
\text { over 2 reps/family }\end{array}$ & Grand mean & 779 \\
& Highest family mean & 1167 \\
& Lowest family mean & 413 \\
$\begin{array}{l}\text { September 2008, } \\
\text { individual plants } \\
\text { sampled }\end{array}$ & Grand mean & 292 \\
& Highest family mean & 422 \\
& Lowest family mean & 192 \\
& LSD $_{5 \%}$ family means & 113 \\
\hline
\end{tabular}

\section{Discussion}

The regular production of $\mathrm{N}$-formyl loline in PRG infected with AR525 confirms earlier results (Easton et al. 2007) and accords with the description of an apparently satisfactory infection (Christensen 1995) and excellent production of peramine (Easton 2007). However, in its natural host, tall fescue, AR525 also produces $N$-acetyl loline and $N$-acetyl norloline (Ball \& Tapper 1999).

Mean herbage loline concentrations of nearly 800 $\mu \mathrm{g} / \mathrm{g}$ in May 2008 are about half those expected of tall fescue in comparable conditions. Combined with high peramine concentrations also present in the herbage, they may be sufficient to effect protection against some invertebrates. Further, they represent a large improvement over concentrations between zero and $200 \mu \mathrm{g} / \mathrm{g}$ measured in the plants originally inoculated.

Maternal HS families differed significantly for herbage loline concentrations on almost all occasions when comparisons were analysed, indicating readily heritable variation in host plant influence on fungal metabolism, as has been shown for other associations (Easton et al. 2002), and already indicated for this one (Easton et al. 2007). Further positive responses to selection for loline concentrations can be expected. The lack of evidence of discrimination from earlier genetic lineage for the October 2007 sampling may be due to the more recent generation of parents being a truncated selection and not randomly representing their maternal lineage from the previous generation.

The data presented here do not compare generations, and a discriminating experiment to determine response to selection, and therefore verify the reality of useful heritable variation is essential.

Increasing concentrations of loline in herbage is not the only requirement of a useful association. Efficient

Table 4 Frequency of infection of perennial ryegrass seedlings with endophyte strain AR525, 27 half sibling families, April 2009.

Frequency of endophyte infection \%

Grand mean 75

Highest family mean 99

Lowest family mean 30

transmission of endophyte to seed, robustness in the seed and effective infection of the new seedling, at high frequency, are all essential. Transmission through a plant and into seed requires the endophyte to establish in every meristem as it forms. For a tall fescue association, a small degree of failure was observed (Wilson \& Easton 1997) at all meristem levels (tiller, panicle branch, spikelets on branches).

The verified infection in spring 2007 of all tillers on almost all seedlings identified as infected the previous autumn is encouraging. Allowing for a small number of false negative results, this indicates there are few losses of endophyte from infected tissues, and almost no emergence of non-infected sectors on infected plants.

The data indicate differences between families (Tables 2 \& 4), but seedlings in a HS family are all from seed carried on one plant, so these frequencies are a non-replicated metric from each of a group of plants. Grouping the plants by maternal lineage failed for both data sets to identify any clear host genetic effect. Removing from the data set a few poorly infected families outside the continuous range did not change the situation.

Significantly higher infection frequencies were achieved in autumn 2009 than in the previous year, but these data sets are not comparable. The germination and infection tests were not completed together, and the seed was harvested under different conditions. Again, a controlled experiment is needed.

There clearly are outstanding differences between families (that is, between seed lots harvested from different plants in the same plot and the same year), and even if there are genetic effects not evidenced in our data, it is likely other factors are in part driving the results. The 2009 results indicate that high infection frequencies can be achieved, but we can not do this reliably. There are environment or management factors causing uncontrolled variation. Identifying these factors and controlling them are essential for eventual effective use in ryegrass swards of loline-producing endophyte strains sourced from other grass hosts. 


\section{ACKNOWLEDGEMENTS}

Anouck de Bonth verified endophyte infection assays. This research was funded by the Foundation for Research, Science and Technology.

\section{REFERENCES}

Ball, O.J.-P.; Tapper, B.A. 1999. The production of loline alkaloids in artificial and natural grass/endophyte associations. Proceedings of the 52nd New Zealand Plant Protection Conference: 264-269.

Bush, L.P.; Fannin, F.F.; Siegel, M.R.; Dahlman, D.L.; Burton, H.R. 1993. Chemistry, occurrence and biological effects of saturated pyrrolizidine alkaloids associated with endophyte-grass interactions. Agriculture, Ecosystems and Environment 44: 81-102.

Bush, L.P.; Wilkinson, H.H.; Schardl, C.L. 1997. Bioprotective alkaloids of grass-fungal endophyte symbioses. Plant Physiology 114: 1-7.

Christensen, M.J. 1995. Variation in the ability of Acremonium endophytes of Lolium perenne, Festuca arundinacea and $F$. pratensis to form compatible associations in the three grasses. Mycological Research 99: 466-470.

Easton, H.S. 2007. Grasses and Neotyphodium endophytes: co-adaptation and adaptive breeding. Euphytica 154: 295-306.

Easton, H.S.; Christensen, M.J.; Eerens, J.P.J.; Fletcher, L.R.; Hume, D.E.; Keogh, R.G.; Lane, G.A.; Latch, G.C.M.; Pennell, C.G.L.; Popay, A.J.; Rolston, M.P.; Sutherland, B.L.; Tapper, B.A. 2001. Ryegrass endophyte: a New Zealand Grassland success story. Proceedings of the New Zealand Grassland Association 63: 37-46.

Easton, H.S.; Latch, G.C.M.; Tapper, B.A.; Ball, O.J.-P. 2002. Ryegrass host genetic control of concentrations of endophyte-derived alkaloids. Crop Science 42: 51-57.

Easton, H.S.; Lyons, T.B.; Mace, W.J.; Simpson, W.R.; de Bonth, A.C.M.; Cooper, B.M.; Panckhurst, K.A. 2007. Differential expression of loline alkaloids in perennial ryegrass infected with endophyte isolated from tall fescue. Grassland Research and Practice Series 13: 163-165.

Fletcher, L.R.; Harvey, I.C. 1981. An association of a Lolium endophyte with ryegrass staggers. New Zealand Veterinary Journal 29: 185-186.
Kennedy,C.W.; Bush,L.P. 1983. Effect of environmental and management factors on the accumulation of $\mathrm{N}$-acetyl and $\mathrm{N}$-formyl loline alkaloids in tall fescue. Crop Science 23: 547-552.

Latch, G.C.M.; Christensen, M.J. 1985. Artificial infection of grasses with endophytes. Annals of Applied Biology 107: 17-24.

Popay, A.J.; Hume, D.E.; Baltus, J.G.; Latch, G.C.M.; Tapper, B.A.; Lyons, T.B.; Cooper, B.M.; Pennell, C.G.; Eerens, J.P.J.; Marshall, S.L. 1999. Field performance of perennial ryegrass (Lolium perenne) infected with toxin-free fungal endophytes (Neotyphodium spp). Grassland Research and Practice Series 7: 113-122.

Popay, A.J.; Mainland, R.A. 1991. Seasonal damage by Argentine stem weevil to perennial ryegrass pastures with different levels of Acremonium lolii. Proceedings of the 44th New Zealand Weed and Pest Control Conference: 171-175.

Prestidge, R.A.; Pottinger, R.P.; Barker, G.M. 1982. An association of Lolium endophyte with ryegrass resistance to Argentine stem weevil. Proceedings of the 35th New Zealand Weed and Pest Control Conference: 119-122.

Wheatley, W.M.; Simpson, W.R. 2000. Tissue immunoblot procedure - stability of Neotyphodium endophyte antigen on nitrocellulose membrane. pp. 145-147. In: Proceedings of the grassland conference 2000 - 4th International Neotyphodium/grass interactions symposium. Eds. Paul, V. H.; Dapprich, P. D. Universität-Gesamthochschule Paderborn, Abteilung Soest, Fachbereich Agrarwirtschaft, Soest, Germany.

Wilson, S.M.; Easton, H.S. 1997. Seed transmission of an exotic endophyte in tall fescue. pp. 281-283. In: Neotyphodium/Grass Interactions. Eds. Bacon, C. W.; Hill, N. S. Plenum Press, New York \& London.

Yates, S.G.; Fenster, J.C.; Bartelt, R.J. 1989. Assay of tall fescue seed extracts, fractions, and alkaloids using the large milkweed bug. Journal of Agricultural and Food Chemistry 37: 354-357. 